\title{
Seasonal variations of plasma normetanephrine levels in Los Angeles
}

\author{
Run Yu and Meng Wei
}

Cedars-Sinai Health System, 8700 Beverly Blvd, Los Angeles, California 90048, USA

Correspondence

should be addressed to

$\mathrm{R}$ Yu

Email

run.yu@cshs.org

\section{Dear Editor,}

We read with great interest the paper 'Seasonal variation in plasma free normetanephrine concentrations: implications for biochemical diagnosis of pheochromocytoma' published in the March 2014 issue of the European Journal of Endocrinology (1). In that paper, the authors describe $\sim 20 \%$ higher levels of plasma normetanephrine, a biochemical marker of pheochromocytoma, in the winter, in two cities with northern temperate climate. The authors attribute the difference in the plasma normetanephrine levels to the ambient cold temperature in the winter. As the temperature difference between winter and other seasons is much smaller in Los Angeles, CA, USA, a much warmer city with a Mediterranean climate, than in the other two cities, we hypothesized that the seasonal variations of normetanephrine levels should be smaller in Los Angeles.

To test the hypothesis, we gathered data on the date and value of biochemical test results for pheochromocytoma at a large academic hospital in Los Angeles between January 2000 and July 2008 from a database established for two earlier studies $(2,3)$. A total of 407 patients were presented for 445 plasma metanephrines tests during this period. The average age of patient was 53.7 years and $56.5 \%$ of patients were female. All the blood samples for this test were sent to a single reference laboratory with unchanged normal reference range. After excluding patients without clinical diagnosis and those younger than 15 years, who have different normal reference range from that for adults (4), 361 patients (who did 393 tests) had the diagnosis of pheochromocytoma or functional paraganglioma either confirmed (nine patients, $2.5 \%$ ) or excluded (354 patients, 97.5\%) based on a combination of clinical, biochemical, and imaging criteria $(2,3)$. The average plasma metanephrine and normetanephrine levels of the 354 patients without pheochromocytoma in each season of the year are shown in Fig. 1. The age and sex of patients tested in each season were similar. The plasma metanephrine levels did not differ significantly among the four seasons. The plasma normetanephrine levels, however, were significantly higher in the winter than in
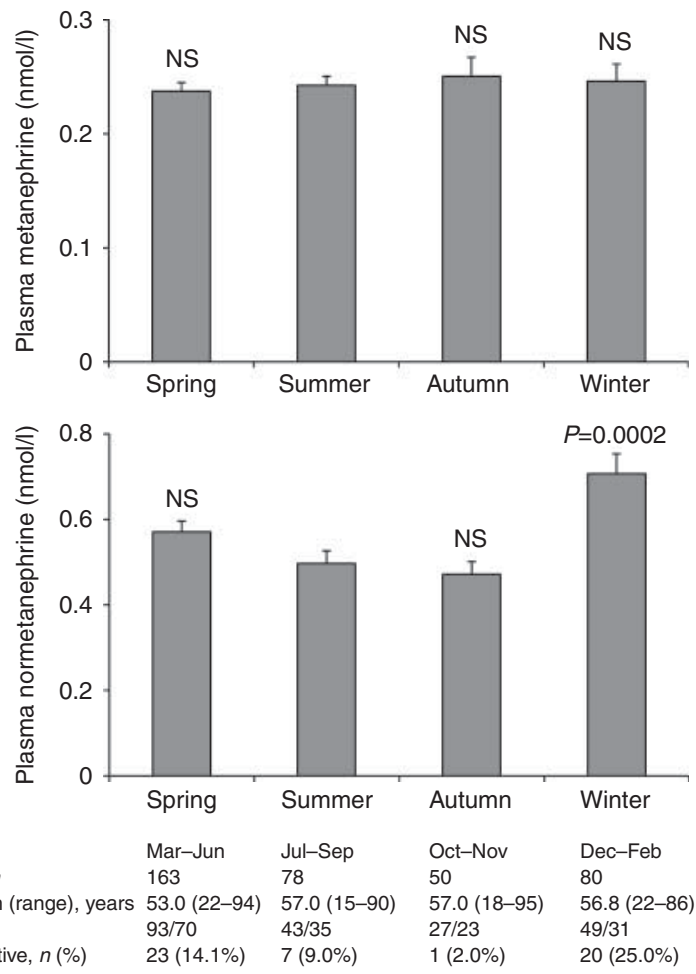

\section{Figure 1}

Plasma metanephrine and normetanephrine levels during the four seasons in Los Angeles, CA, USA. Student's t-test was used to compare the marker levels in the summer and those in other seasons. Because some patients had multiple tests in different seasons, the numbers of patients in the four seasons added together were $>354$, the total number of patients who underwent testing. NS, non-significant. 
the summer $(0.706$ vs $0.496 \mathrm{nmol} / 1,42.3 \%$ higher, $P=0.0002)$. Not unexpectedly, the false positive rate of normetanephrine results was also significantly higher in the winter than in the summer (25 vs $9.0 \%, P=0.0104$ ). There were no significant differences between the normetanephrine levels in the summer and those in the spring and autumn respectively.

To our surprise, the seasonal variations of plasma normetanephrine levels persist in Los Angeles and the variations are indeed very similar in the three cities (1). The average summertime and wintertime temperatures in Los Angeles (23.2 and $14.6^{\circ} \mathrm{C}$ respectively) are both higher but their difference $\left(8.6^{\circ} \mathrm{C}\right)$ is much smaller (http://www. weather.com/weather/wxclimatology/monthly/90089, accessed on February 11, 2014) than the same parameters in the other two cities. Thus ambient temperature difference between the winter and the summer alone cannot explain the difference between the plasma normetanephrine levels in these two seasons. Angelinos may not wear effectively insulating clothing in the winter, so that they are similarly exposed to the drop of temperature in the winter even though the ambient temperature is not very cold. Because false positive test results can lead to overdiagnosis of pheochromocytoma
$(3,5)$, regardless of the underlying mechanisms, the persistent seasonal variations in quite different climates is one more factor to consider in the interpretation of the plasma normetanephrine levels in the diagnosis of pheochromocytoma.

\section{References}

1 Pamporaki C, Bursztyn M, Reimann M, Ziemssen T, Bornstein SR, Sweep FC, Timmers H, Lenders JW \& Eisenhofer G. Seasonal variation in plasma free normetanephrine concentrations: implications for biochemical diagnosis of pheochromocytoma. European Journal of Endocrinology 2014170 349-357. (doi:10.1530/EJE-13-0673)

$2 \mathrm{Yu}$ R. Ordering pattern and performance of biochemical tests for diagnosing pheochromocytoma between 2000 and 2008. Endocrine Practice 200915 313-321. (doi:10.4158/EP09032OR)

$3 \mathrm{Yu}$ R \& Wei M. False positive test results for pheochromocytoma from 2000 to 2008. Experimental and Clinical Endocrinology \& Diabetes 2010 118 577-585. (doi:10.1055/s-0029-1237699)

4 Weise M, Merke DP, Pacak K, Walther MM \& Eisenhofer G. Utility of plasma free metanephrines for detecting childhood pheochromocytoma. Journal of Clinical Endocrinology and Metabolism 200287 1955-1960. (doi:10.1210/jcem.87.5.8446)

5 Eisenhofer G, Goldstein DS, Walther MM, Friberg P, Lenders JW, Keiser HR \& Pacak K. Biochemical diagnosis of pheochromocytoma: how to distinguish true- from false-positive test results. Journal of Clinical Endocrinology and Metabolism 200388 2656-2666. (doi:10.1210/jc.2002030005)

Received 12 February 2014 Accepted 17 February 2014 